\title{
Instructional Design and Motivation in Computer-Based Learning Environment
}

\author{
Yasir Ahmad \\ Department of Computer Science Salman Bin Abdulaziz University, Saudi Arabia
}

\begin{abstract}
After several years of research in learning, education and the reactions of cognitive psychology to this research, educational psychologists and training designers developed prescriptive model for the systematic design of instruction (Derry and lesgold, 1994). This model, called Instructional Design (ID) or Instructional System Design (ISD), consists of knowledge, terminology and procedures that are widely accepted by professionals within the instructional design culture (Dick and Carey, 1990; Gagne and Merrill, 1990). Maximizing the learner motivation should be a major aim in instructional design. In this research article, a motivational theory (Eggen and Kauchak, 1999) and an ISD process (Morrison, 2010, 28) is discussed and few suggestions are furnished in the CBL environment instructions design.
\end{abstract}

Keywords: CBL; motivation; instruction design; Maslow; ADDI.

\section{Role of Motivation}

Motivation can be defined in many ways; depends upon its application. However, according to (Keller and Litchfield, 2002), motivation can be defined as a person's desire to pursue a goal or perform a task. In the educational arena, the goal or task pursued should be student engagement in the learning environment. We know that belonging and relatedness are needs that strongly influence students' motivation to learn (Baurmeister \& DeWall, 2005), and students who don't develop a sense of belonging or identity with their schools have high dropout rates (Juvonen, 2006). Gender differences in interest also exist (Buck, Kostin, \& Morgan, 2002). For instance, males tend to be more interested in topics such as war, politics, hard science, and business, whereas females are more interested in human relationships, arts, literature, marginalized groups, and social reform. Group work, in which students work together toward common learning goals, can also increase involvement (D. W. Johnson \& Johnson, 2006). We often tacitly assume that students who are behaviorally active in hands-on activities and group work are also cognitively active, but this may not be the case. A hands-on activity may be interesting to students but not produce meaningful learning, and group work may do nothing more than help students meet social goals. You must carefully monitor both hands-on and group-work activities to ensure that students are learning, not just enjoying an activity (Brophy, 2010; Mayer, 2004).

\section{ID (Instructional Design)}

Instructional Design (also called Instructional Systems Design (ISD)) is the practice of creating "instructional experiences which make the acquisition of knowledge and skill more efficient, effective, and appealing (Merrill, M. D. et al, 1996). The research on instructional design usually shows hardly any cognizance of student learning, or of anything that would help a teacher to design instruction that facilitates deep rather than surface learning (eg, Kember and Murphy, 1990; Reigeluth, 1983). Instructional designers are claimed to structure both the contect and the methods used to convey lesson content. Content is organized into instructional sequences, and learners procees through prescribed sequences. In case where the external structuring of knowledge and learning of clearly specified content are required, such methods are effective (Hannafin, 1993). However, learning goals and activities are nowadays often less exciplit and identifiable, while being more complex, individual and internally centered, than when addressed via instructional design methods (Kember and Murphy, 1990). According to Kinzie, Julian, and Davis (2004), instructional design is a process of analyzing the learning needs of students with regard to course content, then developing a delivery system to meet those needs.

\section{Maslow's Theory of Motivation}

(Maslow, A. H., 1970) felt as though conditioning theories did not adequately capture the complexity of human behavior. He presented the idea that human actions are directed toward goal attainment. Any given behavior could satisfy several functions at the same time; for instance, going to a pub could satisfy one's needs for self-esteem and for social interaction.

Maslow's Hierarchy of Needs has often been represented in a hierarchical pyramid with five levels as shown in Fig 1. The four levels (lower-order needs) are considered physiological needs, while the top level is 
considered growth needs. The lower level needs need to be satisfied before higher-order needs can influence behavior. The levels are as follows (see pyramid in Figure 1 below).

- Self-actualization - morality, creativity, problem solving, etc.

- Esteem - includes confidence, self-esteem, achievement, respect, etc.

- Belongingness - includes love, friendship, intimacy, family, etc.

- Safety - includes security of environment, employment, resources, health, property, etc.

- Physiological - includes air, food, water, sex, sleep, other factors towards homeostasis, etc.

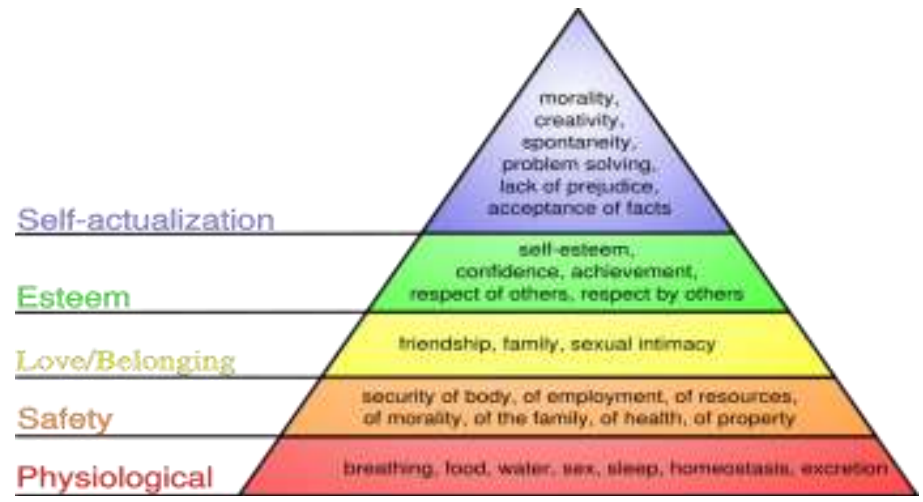

Fig. 1 Maslow's Hierarchy of Needs

\section{Maslow's Theory Limitations}

While a useful guide for generally understanding why students behave the way that they do and in determining how learning may be affected by physiological or safety deficiencies, Maslow's theory has its share of limitations. Some have noted vagueness in what is a "deficiency"; what is a deficiency for one is not necessarily a deficiency for another. Secondly, there seem to be various exceptions that frequently occur. For example, some people often risk their own safety to rescue others from danger.

\section{ADDIE ISD Model}

The ADDIE model is actually a frame work that lists the generic process traditionally used by instructional designers and training developers (Morrison, 2010, 28). The five phases-Analysis, Design, Development, Implementation, and Evaluation - represent a dynamic, flexible guideline for building effective training and performance support tools as shown in figure 2. It is an Instructional Systems Design (ISD) model. Most of the current instructional design models are variations of the ADDIE process (Piskurich, G.M., 2006); other models include the Dick \& Carey and Kemp ISD models. One commonly accepted improvement to this model is the use of rapid prototyping. This is the idea of receiving continual or formative feedback while instructional materials are being created. This model attempts to save time and money by catching problems while they are still easy to fix.

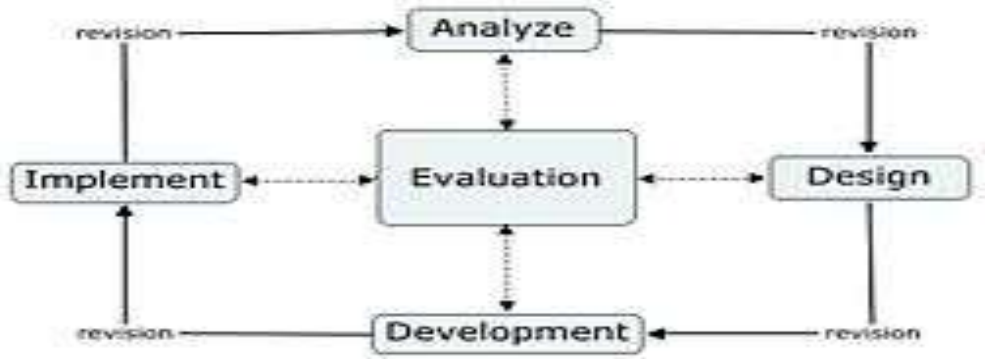

Fig. 2 ADDIE ISD Model

Analysis

In the analysis phase, the instructional problem is clarified, the instructional goals and objectives are established and the learning environment and learner's existing knowledge and skills are identified.

\section{Design}

The design phase deals with learning objectives, assessment instruments, exercises, content, subject matter analysis, lesson planning and media selection. The design phase should be systematic and specific. 


\section{Development}

The development phase is where instructional designers and developers create and assemble the content assets that were blueprinted in the design phase. In this phase, storyboards are created, content is written and graphics are designed. If e learning is involved, programmers work to develop and/or integrate technologies.

\section{Implementation}

During the implementation phase, a procedure for training the facilitators and the learners is developed. The facilitators' training should cover the course curriculum, learning outcomes, method of delivery, and testing procedures.

\section{Evaluation}

The evaluation phase consists of two parts: formative and summative. Formative evaluation is present in each stage of the ADDIE process. Summative evaluation consists of tests designed for domain specific criterion-related referenced items and providing opportunities for feedback from the users which were identified.

\section{Suggestions \& Contribution}

Maslow's hierarchy of needs and ADDIE ISD model can be applied as a combinatorial process to achieve the desired degree of a comprehensive CBL instructions design. This paper mainly focuses on the design phase of ADDIE model; where the instructional designers should analyze the process of learning and motivational needs of the students with regard to course content. Few suggestions have been proposed by the author; in the CBL instruction design process. First; all the concerned parties instruction designers, teacher and learner must be involved in the process of instructions design. The implications like gender, cultural differences, educational backgrounds etc must be certain guidelines that should be kept in mind while designing instructions. This implies that designers and teachers, in designing the instructions should create learner centered environment, informed by motivational theory. Second; real world examples can guide the students to better understand the problem. While designing the instructions visual (presentations, videos etc), and oral along with the subject specific examples can be incorporated which covers the topic comprehensively; human psychology have an inclination to better understand the real world scenarios.

"Suppose a class teacher is explaining the concept of inheritance in the subject of object oriented technology (Java, C\# etc). It is clear from figure 3 that the concept could be better understood by rendering the real world example to the learners.

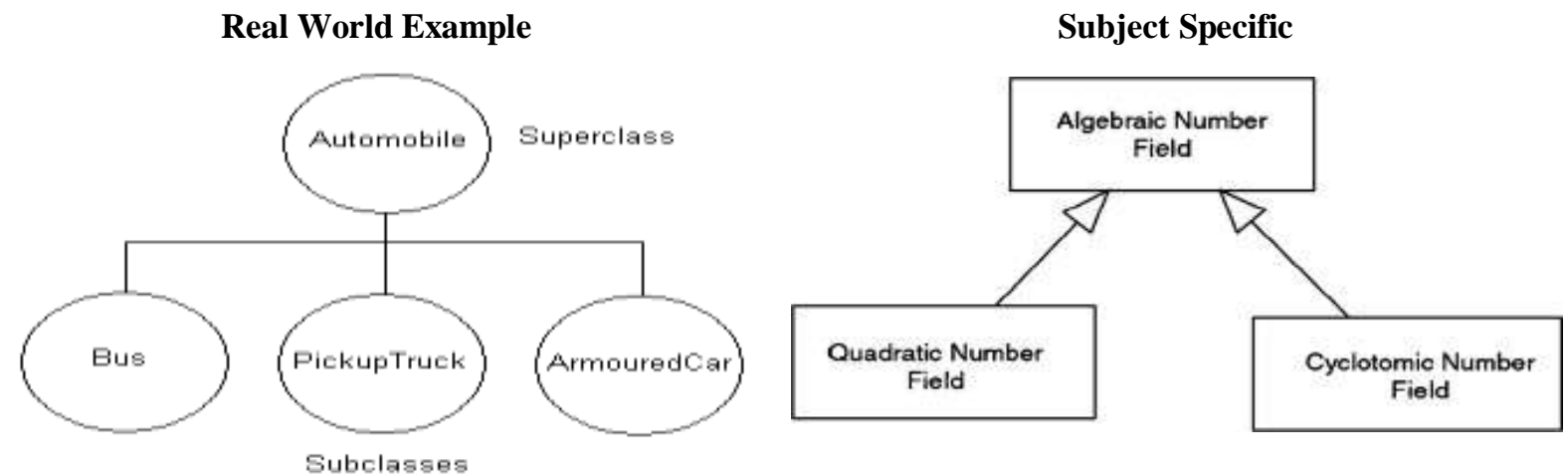

Fig. 3 Inheritance Example (Comparison)

\section{Conclusion}

The major challenge for the field of instructional design is to seriously recognize the significance of participating all the concerned parties like, designers, teachers and learners. It is important to keep in mind that the quality of instructional design is highly dependent on the fit between the design model and its intelligent use by the designer (Hakkinen, 1996; Lowyck and Poya, 2001). The instructional designers have not been very open to new alternatives; they have not reassessed the basic foundations or assumptions of the models (Hannafin, 1993). Through the spectrum of Maslow's hierarchy needs and the instructions strategy discussed above; the designers and teachers can meet the expectations of the learners. In this article few suggestions have been proposed in the process of analyzing the learning and motivational needs of the students while designing the CBL instruction. 


\section{References}

[1] Derry S et al (1994) Toward a Situated Social Practice Model for Instructional Design Draft, May.

[2] Dick W et al (1990) The System Design of Instruction (34d ed) Scott Foresman, Glenview.

[3] Gagne R M et al (1990) Integrative goals for Instructional Design Educational Technology Research and Development 38 (1) 23 30 .

[4] Eggen, P., \& Kauchak, D. (1999). Educational psychology: Windows on classroom (pp.404-407).

[5] Upper Saddle River, NJ: Merrill Prentice Hall.

[6] Morrison, Gary R. Designing Effective Instruction, 6th Edition. John Wiley \& Sons, 2010.

[7] Keller J., \& Litchfield B. (2002) Motivation and performance. In R.A. Reiser \& J.V. Dempsey (Eds.), Trends and Issues in Instructional Design and Technology (pp. 83-98). Upper Saddle River, NJ: Merrill Prentice Hall.

[8] Baumeister, R. F., DeWall, C. N., Ciarocco, N. J., \& Twenge, J. M. (2005). Social exclusion impairs self-regulation. Journal of Personality and Social Psychology, 88, 589-604.

[9] Juvonen, J. (2006). Sense of belonging, social relationships, and school functioning. P. A. Alexander and P. H. Winne (Eds.), Handbook of Educational Psychology, 2nd edition (pp. 255-674). Erlbaum, Mahwah, NJ.

[10] Buck, G., Kostin, I., \& Morgan, R. (2002). Examining the relationship of content to gender-based performance differences in Advanced Placement Exams. (College Board Research Report No. 2002-12). New York: The College Board.

[11] Johnson, D. W., \& Johnson, F. (2006). Joining Together: Group theory and group skills ( $9^{\text {th }}$ Ed.). Boston: Allyn \& Bacon.

[12] Brophy, Jere E., (2010). Motivating Students to Learn. Edition 3, illustrated, revised, Publisher: Taylor \& Francis, ISBN 0415800692, 9780415800693. Length 343 pages.

[13] Mayer, R. E. (2004). Should there be three-strikes rule against pure discovery learning? The Case for guided methods of instruction. American Psycologist, 59(1), 14-19.

[14] Merrill, M. D., Drake, L., Lacy, M. J., Pratt, J., \& ID2_Research_Group. (1996). Reclaiming instructional design. Educational Technology, 36(5), 5-7

[15] Kember F et al (1990) Alternative new directions for instructional design Educational Technology 30 (8) $42-47$.

[16] Reigeluth C M (ed) (1983) Instructional design theories and models: An overview of their current status Lawrence Erlbaum, Hillsdale, NJ.

[17] Hannafin M J (1993) Emerging technologies, ISD, and learning environments: critical perspectives Educational Technology research and Development 40 (1) 49-63.

[18] Kinzie, M.B., Julian, M. F., \& Davis, W. C. (2004). Instructional design. In AKovalchick and K. Dawson (Eds.), Education and Technology: An Encyclopedia (pp. 330-337). Santa Barbara, CA: ABC-CLIO.

[19] Maslow, A. H. (1970). Motivation and Personality, 2nd. Ed., New York, Harper \& Row. ISBN 0060419873.

[20] Piskurich, G.M. (2006). Rapid Instructional Design: Learning ID fast and right.

[21] Hakkinen P (1996) Design, Take into Use and Effects of Computer-Based Learning Environments - Designer's. Teacher's and Student's Interpretation University of Joensuu, Publications in Education. No. 34, Joensuu (Doctoral Dissertation).

[22] Lowyck J et al (2001) Design of collaborative learning environments Computers in Human Behaviour 17 607-516.

[23] Reiser, R. A. \& Dick, W. (1996). Instructional planning. Boston, MA: Allyn and Bacon. 